\title{
INFLUENCE AND EVALUATION OF CONSTRAINT ON FRACTURE TOUGHNESS IN PIPELINE RESEARCH
}

\author{
M. Verstraete ${ }^{1}$, W. De Waele ${ }^{1}$, S. Hertelé ${ }^{1}$ and R. Denys ${ }^{1}$ \\ ${ }^{1}$ Ghent University, Laboratory Soete, Belgium
}

\begin{abstract}
Accessing nowadays fossil fuel reserves requires a strain-based design approach. Within such design, the ductile tearing resistance is a key parameter in assessing the defect tolerance. To determine this tearing resistance, full scale (pressurized) tests can be performed. However, such approach would be costly and time consuming. Consequently, effort is made to select appropriate small scale test specimens. Most research has focused so far on the single edge notch bend (SENB) and tensile (SENT) specimen. To evaluate the suitability of these test specimens, the crack tip stress fields can be examined or the resistance curves compared with full scale structures. This paper aims at comparing the trends observed using these techniques. Furthermore, the suitability of the small scale test specimens is evaluated. It is concluded that sufficiently long (length-to-width ratio equal to ten) clamped SENT specimens have the potential to predict the tearing resistance of full scale pipes. In addition, the internal pressure does not significantly affect the fracture toughness. These conclusions are stated by both experimental results and finite element simulations.
\end{abstract}

Keywords: resistance curve; constraint; crack tip stress fields; SENT; pipeline

\section{INTRODUCTION}

Seen the diminishing fossil fuel reserves and the ever increasing demands, large effort is put in accessing sources located in more and more challenging environments. As an example, the discovery of two major oil fields in the Barentz sea has recently been reported (Skrugard and Havis [1]). A possible way to accommodate these oil reserves is by constructing pipelines crossing both sea and land. Since these oil fields are located in the arctic regions, these pipelines should exhibit superior low temperature properties. Next to the temperature aspects, such pipelines potentially cross areas prone to frost heave or thaw settlement. These loading conditions necessitate a so-called strain-based design (SBD) approach, since the loading is displacement rather than force controlled [2]. Within such SBD, effort is made to predict the pipelines' defect tolerance as the girth welds connecting the pipe sections are sensitive to defects.

It is widely acknowledged that one of the key parameters in strain based defect assessment is the ductile tearing resistance [3]. Consequently, an accurate determination of the tearing resistance is required. Although full scale tests unmistakeably yield representative results, such tests are both costly and timeconsuming. As a result, different small scale fracture toughness test specimens have been developed ever since the origin of fracture mechanics theory [4].

It is well understood that the fracture toughness of a material is not only a material property but might also be influenced by the loading conditions and geometry of the test specimen. Accordingly, different toughness values can be expected from the fracture mechanics test specimen. Therefore, it is not clear which specimens yield resistance curves representative for (pressurized) pipes. To gain insight in the obtained fracture toughness values, the authors have performed a literature review, comparing the results from commonly used fracture mechanics test specimens to full scale pipe test results. The considered small scale specimens are the standardized Single Edge Notch Bend (SENB) specimen (see Fig. 1a and [5]) and two variants of the Single Edge Notch Tensile (SENT) specimen, namely the clamped SENT specimen (see Fig. 1b) and the pin-loaded SENT specimen (see Fig. 1c). The difference between the last two variants is in the boundary conditions, the first one restricts all rotations while the second allows rotations in the loading points. 
(a)

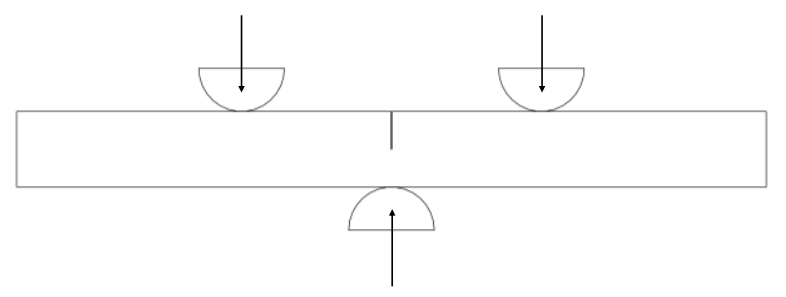

(b)

(c)

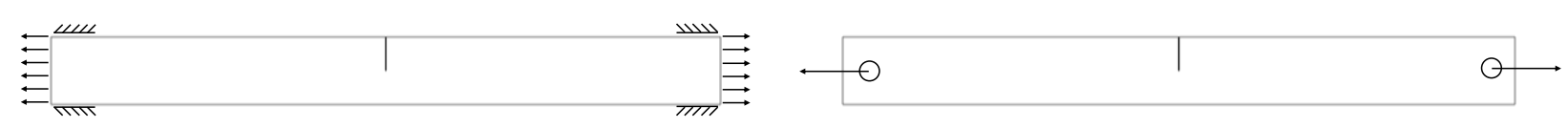

Fig. 1 Schematic representation of fracture mechanics test specimens considered in this paper :

SENB (a), clamped SENT (b) and pin-loaded SENT (c)

\section{NUMERICAL ANALYSIS OF CRACK TIP STRESS FIELDS}

A first way of assessing the potential difference between different fracture toughness test specimens and the actual full scale structure, is by analyzing the stress fields ahead of the crack tip. Under equivalent loading conditions, these should represent a similar degree of triaxiality, supposing. To date, a wide range of theoretical frameworks have been developed. This section provides a description of the most promising ones.

\subsection{JQ-theory}

Developed in the early 1980's, the $J-Q$ theory aims at predicting the actual shape and magnitude of the crack tip stress fields. Therefore two parameters are considered, namely J-integral and the $Q$-parameter [6, 7]. At first, it is assumed that for non-linear elastic materials (Ramberg-Osgood constitutive law) the shape of the crack tip stress fields is described by the Hutchinson-Rice-Rosengren (HRR) formulation [4].

$$
\sigma_{i j}=\sigma_{0}\left(\frac{E J}{\alpha \sigma_{0}^{2} I_{n} r}\right)^{1 / n+1} \tilde{\sigma}_{i j}(n, \vartheta)
$$

However, this formulation was later on modified to allow other material definitions as well. Consequently, the HRR solution was no longer considered as the reference solution. Alternatively, the small scale yielding (SSY) solution was considered. This SSY solution is obtained from the analyses of the crack tip stress field in a high constraint Modified Boundary Layer (MBL) model [8]. It should be noted that both the shape and magnitude of the SSY and HRR formulation do not differ significantly for Ramberg-Osgood materials [9].

Second, the Q-parameter is introduced to characterize the magnitude of the $\sigma_{\theta \theta}$ stress field ahead of the crack tip. This $Q$-parameter is defined by the difference between the actually observed crack tip opening stress and the reference stress:

$$
\mathrm{Q}=\frac{\sigma_{\vartheta \vartheta}-\left(\sigma_{\vartheta \vartheta}\right)_{\mathrm{SSY}}}{\sigma_{0}}
$$

Although theoretically independent of the distance ahead of the crack tip, this difference is typically evaluated at a normalized distance ahead of the crack tip equal to:

$$
r=2 J / \sigma_{0} \text { and } \vartheta=0
$$


Consequently, the Q-parameter describes a hydrostatic shift of the crack tip stress field, thereby characterizing the triaxiality at the crack tip. This implies that positive $Q$-values increase the magnitude of the crack tip stress fields while negative values correspond to a decrease.

Based on the so-obtained $J$ and $Q$ parameters, a $J-Q$ trajectory can be constructed. This reflects the degree of constraint (in terms of $Q$ ) at subsequent loading levels (defined by the J-integral). Note furthermore that using this description, the $J$-integral can be seen as setting the size scale of the plastic zone, while the $Q$-parameter determines the magnitude of the stress fields.

\section{$2.2 \quad$ Triaxiality parameter $h$}

A second method used to describe the triaxiality at the crack tip, makes use of the first and second invariant of the stress tensor. The first invariant, the hydrostatic stress, does not represent any plastic deformation. In contrast, the second invariant, which corresponds with the Von Mises equivalent stress, represents the amount of plastic deformation. Consequently, the ratio of both can be seen a measure for the resistance against plastic deformation $[10,11]$.

$$
\mathrm{h}=\frac{\sigma_{\mathrm{m}}}{\sigma_{\mathrm{v}}}=\frac{\frac{1}{3}\left(\sigma_{\mathrm{xx}}+\sigma_{\mathrm{yy}}+\sigma_{\mathrm{zz}}\right)}{\frac{1}{\sqrt{2}}\left[\left(\sigma_{\mathrm{xx}}-\sigma_{\mathrm{yy}}\right)^{2}+\left(\sigma_{\mathrm{yy}}-\sigma_{\mathrm{zz}}\right)^{2}+\left(\sigma_{\mathrm{zz}}-\sigma_{\mathrm{xx}}\right)^{2}\right]^{1 / 2}}
$$

The distance ahead of the crack for the evaluation of this $h$-parameter is arbitrarily chosen equal to the distance used for the $Q$-parameter. Noteworthy is also the link between this h-parameter and the $Q$-parameter as defined in the previous paragraph. Through the analysis of crack tip stress fields in compact tension (CT) and SENB specimens, a linear relation between both parameters has been observed (see Fig. 2).

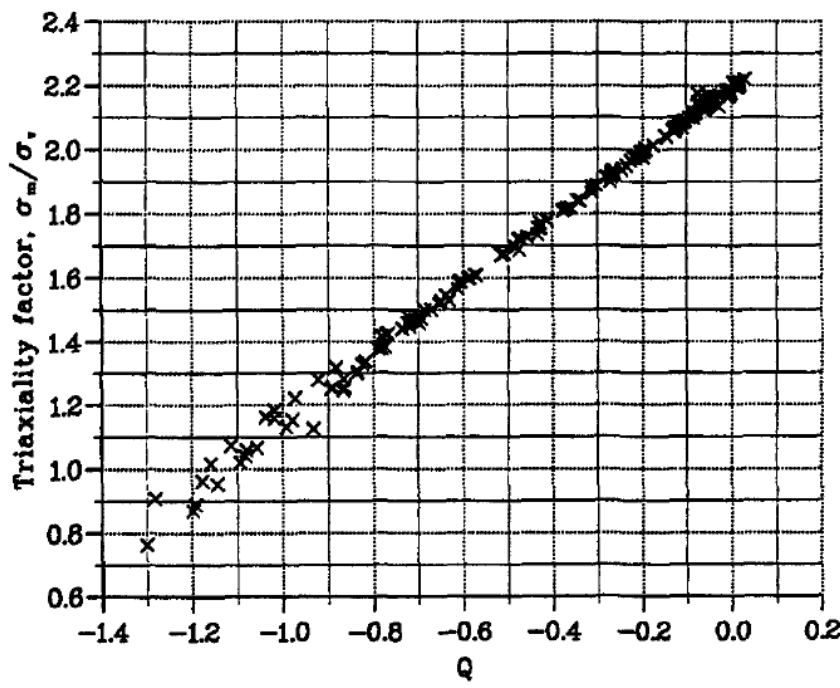

Fig. 2 Relation between $Q$-parameter (x-axis) and triaxiality parameter (y-axis) obtained from the analysis of crack tip stress fields in both SENB and CT specimens [10]

\subsection{Linking constraint calculations to resistance curves}

Evidently, the above constraint calculations should link to the resistance curves. Considering the $J$-integral as a fracture parameter, the resistance curve is generally described as follows:

$$
\mathrm{J}(\Delta \mathrm{a})=\mathrm{C}_{1}(\Delta a)^{C_{2}}
$$

Additionaly, the above theoretical frameworks assume that this curve depends on the triaxiality level ahead of the crack tip. Assuming that this triaxiality can be appropriately described by the Q-parameter, this relation can be extended as follows [12, 13]: 


$$
\mathrm{J}(\Delta \mathrm{a}, \mathrm{Q})=\mathrm{C}_{1}(\mathrm{Q})(\Delta a)^{C_{2}(Q)}
$$

In the above equation, both $C_{1}$ and $C_{2}$ depend on the triaxiality level. Accordingly, a clear link can be established between the constraint calculations and the resistance curves of different cracked structures. This link allows correcting a known resistance curve to different constraint conditions. To the author's believe such correction should be seen as a theoretical link rather than a practical tool, the selection of a test specimen that shows matching constraint levels is of primary interest. In case such specimen is inexistent, one can think of a constraint correction in accordance to the above framework. Example studies using such correction have been reported in literature, indicating that in particular the $C_{2}$ parameter shows a high dependence on the constraint level [14].

\section{RESISTANCE CURVES}

The objective of selecting an appropriate fracture test specimen, is to end up with a specimen that allows determining the resistance curve of a pressurized pipe from the small-scale test specimen. Ideally, the resistance curves should match between the actual structure and the test specimen. These curves can be obtained from finite element simulations or experimental data.

\subsection{Finite Element Analysis: Gurson-Tvergaard-Needleman damage model}

The main advantage of numerical data over experimental data is the absence of scatter, e.g. originating from heterogeneous material properties. However, the damage models incorporated in the finite element software should embody the physical principles that govern fracture. A commonly used, and validated [11], approach is based on the damage model developed by Gurson and later on modified by Tvergaard and Needleman. In this model, the material damage is described by the following function:

$$
\Phi=\left(\frac{\sigma_{v}}{\sigma_{\text {flow }}}\right)^{2}+2 q_{1} f \cosh \left(\frac{3 q_{2} \sigma_{m}}{2 \sigma_{\text {flow }}}\right)-\left(1+q_{3} f^{2}\right)=0
$$

Remark that, using this formulation, the Von Mises equivalent stress and the hydrostatic stress determine the material's damage. This supports the use of the triaxiality parameter $h$ for the assessment of triaxiality at crack tip. For a more in depth description of the GTN damage model, the reader is referred to the literature [15-19].

\subsection{Experimental results}

A wide variety of fracture mechanics tests has been reported in literature. Mostly, the crack tip opening displacement (CTOD) is adapted as crack driving force parameter, in contrast to the $\mathrm{J}$-integral reviewed for constraint calculations. To the authors' experience, this is attributed to the measurability of the CTOD. This parameter can straightforwardly be measured during a test; it does not require any additional calculations, potentially relying on assumptions (e.g. regarding material properties). This contrasts the J-integral concept, which is unquestionably of large theoretical importance, but can hardly be measured during a (full scale) test.

\section{DISCUSSION}

This paragraph provides an overview of the most relevant constraint related results reviewed in literature. It comprises both results obtained from finite element analysis and experimental results.

\subsection{Influence of deformation level}

In general, it is observed that as plasticity develops at the crack tip, the triaxiality decreases ahead of the crack tip. Regarding pipes, this observation is particularly striking for the deepest point of the crack, near the free surface this effect is far less pronounced [20]. The amount of decrease strongly depends on the material properties; both the yield strength and the strain hardening behavior influence the $J-Q$ trajectories. It has been observed from multiple finite element studies that lower $Y / T$-ratios result in lower constraint levels (see Fig. 3) [21, 22]. A higher yield strength increases the triaxiality level for equal load levels in terms of $J$-integral [22]. From these observations, it can be concluded that higher local plasticity levels in 
general yield lower triaxiality levels for equal crack driving forces. Accordingly, in more general terms plasticity is related to the fracture toughness. This is not surprising as the constraint can be perceived as a structural obstacle against plastic deformation [23].

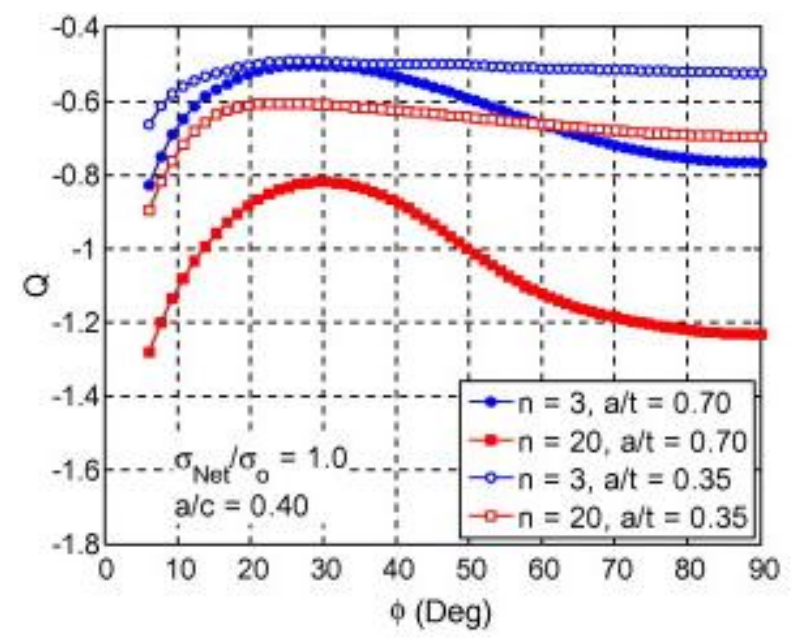

Fig. 3 Influence of Ramberg-Osgood strain-hardening exponent on the Q-parameter in simulations of SENB specimens [21]

\subsection{Influence of loading conditions (SENB versus SENT)}

The loading mode has a significant influence on the triaxiality level ahead of the crack tip and thus on the tearing resistance. It is nowadays generally acknowledged that SENB specimens have a higher constraint and lower ductile tearing resistance compared to SENT specimens (see Fig. 4) [24-28]. This increased constraint originates from the presence of compressive stresses in the cracked ligament, originating from the bending of the specimen. Accordingly, plastic deformation around the crack tip is hindered and limited to a narrower zone with tensile stresses.

Regarding the SENT specimens, a significantly different behavior is observed between pin-loaded and clamped specimens. In general, the clamped specimens show lower constraint levels. This observation again relates to the presence of bending stresses in the cracked ligament. For the clamped specimen, the bending of the specimen is hindered by the boundary conditions. In contrast, the pin-loaded specimen has the potential to bend. The resulting bending stresses increase the constraint level, analogous to the SENB specimen, however less pronounced.

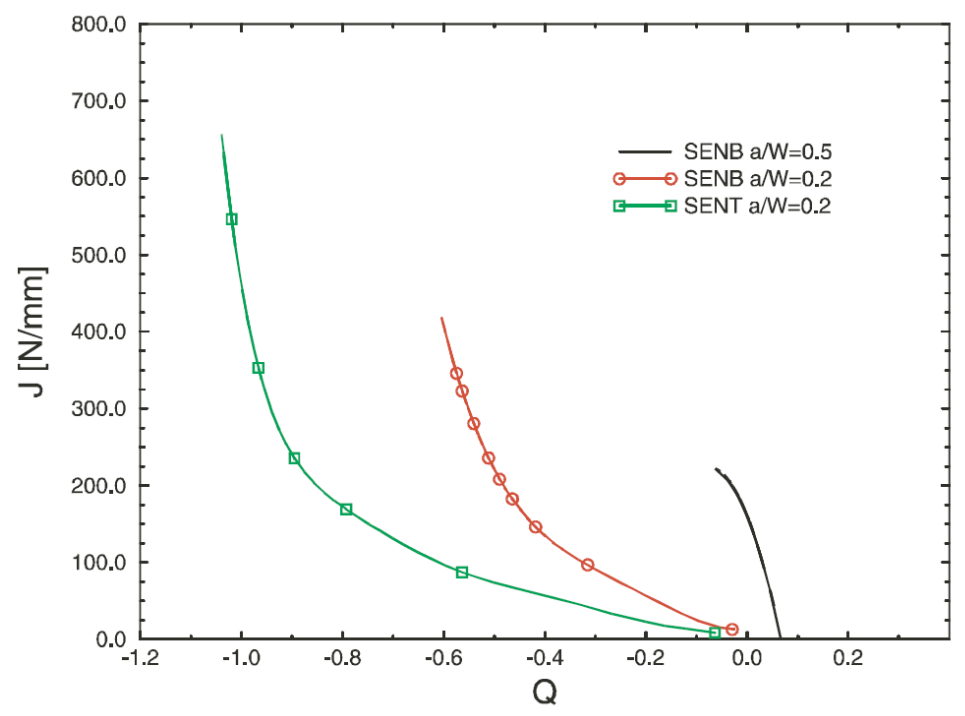

Fig. 4 Comparison of $J-Q$ trajectories between SENT and SENB specimens [26] 


\subsection{Influence of relative crack depth}

Regarding the SENB and SENT specimens, multiple studies have been completed on evaluating the influence of crack depth on the tearing resistance. Both $J-Q$ studies and experimental data confirm that lower relative crack depths decrease the triaxiality level ahead of the crack tip and thereby increase the tearing resistance. However, this effect is less pronounced for clamped SENT specimens [29].

This effect can again be understood considering the relative importance of the bending stresses. At first, SENB specimens are considered. For low relative crack depths, and thus relatively large uncracked ligament sizes, the development of a plastic zone at the crack tip is only marginally affected by the presence of compressive stresses opposite to the cracked surface. This contrasts the situation for large relative crack depths. For large relative crack depths the bending stresses interfere more significantly with the tensile stresses at the crack tip. Accordingly, higher constraint levels are observed, reflected by a lower tearing resistance (see Fig. 5a).

Second, the pin-loaded SENT specimens are examined. For lower relative crack depths, the bending component is far less pronounced as the resulting force in the cracked ligament is closer to the load line of the externally applied forces. In addition, the still present bending stresses do not significantly influence the crack tip stress fields. For deeply notched SENT specimens however, the bending component is much higher and the resulting bending stresses also more easily interact with the crack tip stress fields as the uncracked ligament is smaller. This explains the pronounced difference in obtained fracture toughness between shallow and deeply notched pin-loaded SENT specimens. It should furthermore be noted at this point that this trend is close to independent to the specimen's length, since the bending stresses are not influenced by the length of the specimen either.

Third, the clamped SENT specimens are considered. For these specimens, the influence of the relative crack depth highly depends on the clamping distance. As observed from published $J-Q$ trajectories, small clamping distances (e.g. length-to-width ratio equal to four) show close to now effect of the relative crack depth on the constraint level. This is because they have the tendency to completely prevent bending in the specimen. In contrast, larger clamping distances (e.g. length to width ratio equal to 10) allow bending of the specimen through the elastic deformation of the specimen itself. Accordingly, mechanisms similar to the ones influencing the fracture toughness in pin-loaded specimens become increasingly important (see also Fig. 5b).

For pipes finally, the relative crack depth also affects the constraint level. The higher the relative crack depth, the lower the constraint level $[11,29]$. This again relates to the presence of bending stresses in the cracked ligament.

(a)

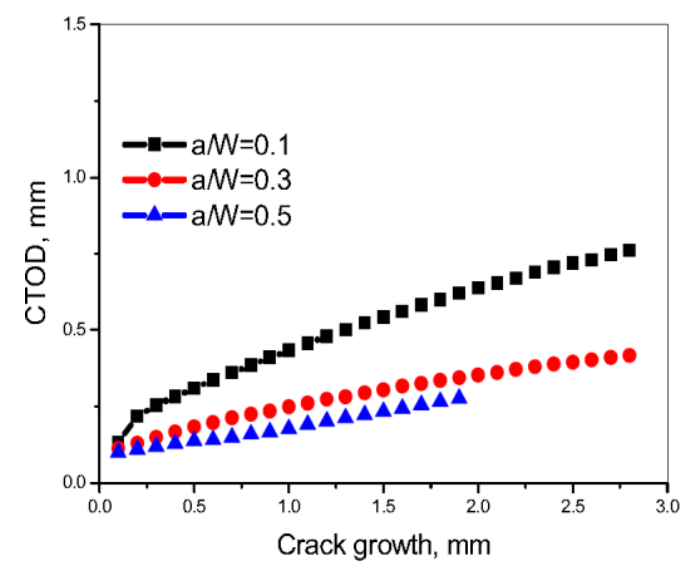

(b)

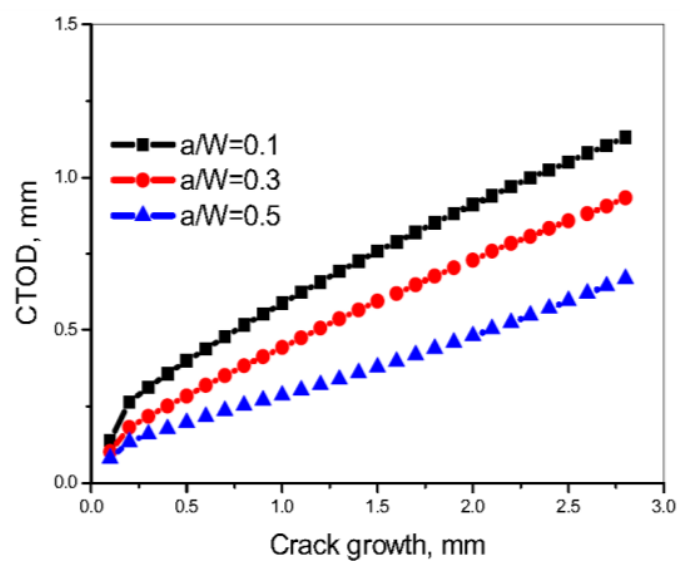

Fig. 5 Influence of relative crack depth $(a / W)$ for SENB (a) and clamped SENT specimens (b) with a length-to-width ratio equal to 10 for the SENT specimens [30]

\subsection{Influence of biaxial loading}

Different constraint analyses for pipes have been reported. Of particular interest are the trends observed for analyses incorporating both pressurized and unpressurized pipes and thus biaxial loading. Typically, different internal pressure levels are examined. This internal pressure is typically expressed in the hoop stress going with the pressure level $\left(\sigma_{\text {hoop }}\right)$. Hoop stresses slightly below the yield strength of the material, e.g. $72 \%$ or $80 \%$ of the specified minimum yield strength, are of practical interest. 
Considering the internal pressure effect, it has been observed that the $J-Q$ trajectories as well as the $J-h$ trajectories are comparable for pipes with and without pressure (see Fig. 6a), indicating that the triaxiality at the crack tip is not significantly influenced by the biaxial loading [11, 31-33]. Indeed, experimentally obtained resistance curves from pressurized and unpressurized pipes indicate that the internal pressure does not significantly shift the resistance curve. The reported differences approximate the measurement accuracy [25, 34]. From resistance curves obtained through finite element simulations, the same can be concluded (see Fig. 6b) [11, 27, 35].

(a)

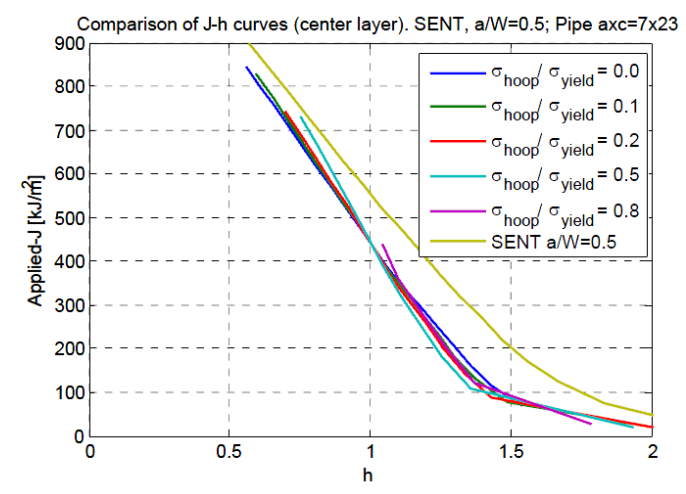

(b)

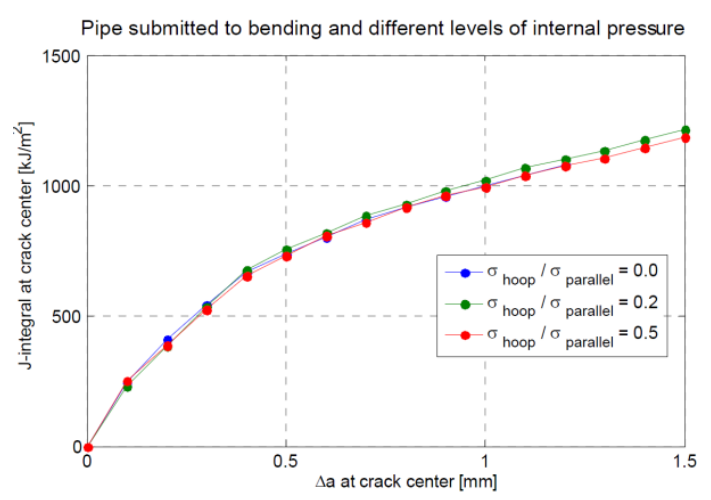

Fig. 6 Influence of internal pressure on triaxiality level from crack tip stress field analyses (a) and influence on resistance curves (b) [11]

\subsection{Small scale test specimens versus full scale pipes}

Traditionally, deeply notched single edge notch bend (SENB) specimens, with a relative crack depth about one half of the specimen's height, have been used for the characterization of the material's fracture toughness. However, if the $J-Q$ trajectories are compared to the ones obtained from pipe specimens, it is typically observed that the SENB specimen shows a significantly higher degree of triaxiality at the crack tip. This reflects a fairly conservative situation. Although this conservativeness might decrease if lower relative crack depths would be considered, the SENB specimens are unlikely to yield resistance curves representing the actual pipe toughness [26, 36].

Next to the SENB specimen, the SENT specimen is compared to the full scale (pressurized) pipe. First, the pin-loaded specimens are considered. For these specimens, it is observed that the $J$ - $Q$ trajectories predict the same trend as compared to full scale pipes, although they are slightly conservative. This conservativeness originates from an overestimation of the bending component in the pipes.

Second, the clamped SENT specimens are compared to pipes. An important choice here is a proper selection of the specimens' length-to-width ratio, as the length of the specimen significantly influences the bending in the specimen. It is observed that specimens with a length-to-width ratio equal to 10 have $J-Q$ and $J$ - $h$ trajectories match the trajectories obtained from pipes with different internal pressure levels (see Fig. 6a). In addition, different experimental studies have reported comparable resistance curves for clamped SENT specimens and (pressurized) pipes (see Fig. 7) [34, 37, 38]. Although, it should be noted that such length-to-width ratios might promote the presence of bending stresses in the cracked ligament. Therefore, the relative crack depth again influences the constraint ahead of the crack tip. Accordingly, it is advised to use so-called "constraint-matched" specimens with a relative crack depth equal to the one of the assessed defects in the full pipes [36]. 


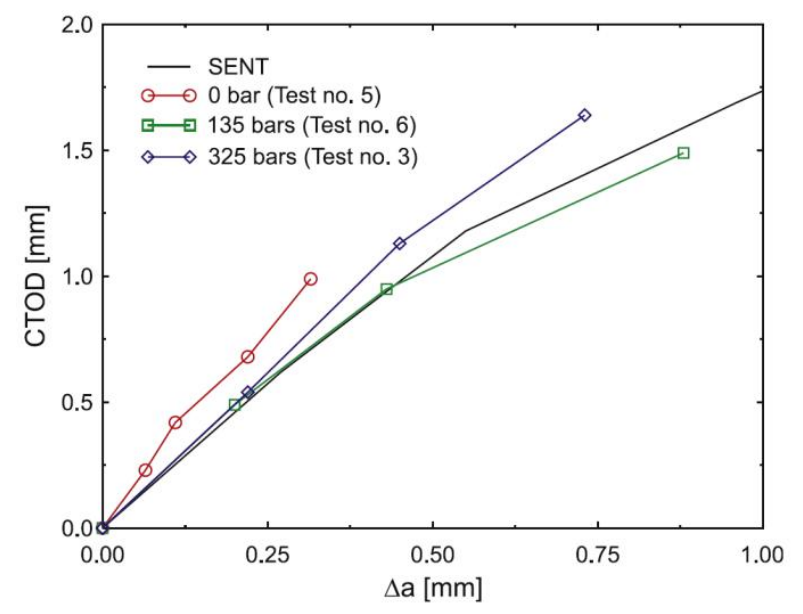

Fig. 7 Reported correspondence between tearing resistance curves obtained from full scale tests with varying internal pressure levels and SENT specimens with comparable relative crack depth [38]

In accordance to these observations, effort is currently made to develop a standardized procedure for SENT testing [39]. It should not surprise that the length-to-width ratio prescribed by this procedure equals 10 , neither should the clamped boundary conditions.

\section{CONCLUSION}

A proper determination of the material's tearing resistance curve is a key issue within a strain-based design context. Accordingly, a proper determination is of primary importance. Although these curves can be obtained from full scale testing, small scale fracture mechanics test specimens can be used, if properly selected. Regarding this selection, the following techniques have successfully been applied, yielding consistent results:

- Analysis and description of crack tip stress fields using either the Q-parameter or the h-parameter to describe the triaxiality in the zone governing fracture. Examination of the $\mathrm{J}-\mathrm{Q}(\mathrm{J}-\mathrm{h})$ trajectories allows estimating the relative fracture toughness.

- Finite element simulations using the Gurson-Tvergaard-Needleman damage model. The so obtained resistance curves can be compared.

- Experiments on a variety of test specimens using the same materials. These data represent the nature of the problem, yet are susceptible to scatter.

Based on these above methods, the following conclusions can be drawn regarding the characterization of pipeline steels:

- The ductile tearing resistance is unaffected by the internal pressure.

- Single Edge Notch Bend specimens yield overly conservative predictions, even for shallow notched specimens.

- Single Edge Notch Tensile specimens have the potential to yield representative fracture toughness results. Although, attention should be paid to select appropriate clamping conditions and specimen dimensions. A length-to-width ratio equal to 10 is advised, whereas the specimen is ideally loaded using clamped grips rather than considering a rotating connection. The relative crack depth in the SENT specimens ideally matches the relative crack depth in the pipe.

- Larger relative crack depths yield conservative predictions of the tearing resistance curves. 


\section{NOMENCLATURE}

$\alpha \quad$ Ramberg-Osgood material parameter

$\vartheta \quad$ Angular position relative to crack face radials

$\sigma_{0} \quad$ Yield strength $\quad \mathrm{MPa}$

$\sigma_{\text {hoop }}$ Stress in circumferential direction $\quad \mathrm{MPa}$

$\sigma_{i j} \quad$ Stress component $(i, j) \quad \mathrm{MPa}$

$\sigma_{m}$ Hydrostatic stress $\quad \mathrm{MPa}$

$\sigma_{v} \quad$ Von Mises equivalent stress $\quad \mathrm{MPa}$

$\tilde{\sigma}_{i j} \quad$ Dimensionless function

$\sigma_{\text {flow }}$ Flow stress $\quad \mathrm{MPa}$

a Crack height $\mathrm{mm}$

CTOD Crack Tip Opening Displacement $\mathrm{mm}$

$\Delta a$ Ductile crack extension $\mathrm{mm}$

E Young's modulus $\quad \mathrm{MPa}$

$f \quad$ Void volume fraction -

$h \quad$ Triaxiality parameter

$I_{n} \quad$ Integration constant

$J$ J-integral N/mm

$n \quad$ Ramberg-Osgood strain hardening exponent

$q_{i} \quad$ Damage parameter

Q Constraint parameter

$r$ Radial distance ahead of crack tip $\mathrm{mm}$

$t \quad$ Wall thickness of pipe test specimens $\mathrm{mm}$

$W \quad$ Wall thickness of fracture test specimens $\mathrm{mm}$

\section{ACKNOWLEDGEMENTS}

The authors would like to acknowledge the financial support of the IWT (Agency for innovation by science and technology - grant $n^{\circ}$ SB-091512 and SB-093512) and the FWO (Research Foundation Flanders grants $\mathrm{n}^{\circ} 1.1 .880 .09 . \mathrm{N} .00,1.1 .880 .11 . \mathrm{N} .01$ and 1.5.247.08N.00). 
1. Statoil. Major oil discovery in the Barents Sea. 2011 [cited 2012 13-01]; Available from: http://www.statoil.com/en/NewsAndMedia/News/2011/Pages/01AprSkrugard.aspx.

2 . Lillig, D.B., The first (2007) ISOPE strain-based design symposium - a review, in International offshore and polar engineering conference. 2008: Vancouver, BC, Canada.

3. $\quad$ Fairchild, D.P., Crawford, M.D., Cheng, W., Macia, M.L., Nissley, N.E., Ford, S.J., Lillig, D.B. and Sleigh, J., Girth welds for strain-based design pipelines, in International offshore and polar engineering conference. 2008: Vancouver, BC, Canada.

4. $\quad$ Anderson, T.L., Fracture mechanics: fundamentals and applications. 1995.

5. ASTM, E1820 - Standard test method for measurement of fracture toughness. 2011, American Society of Testing and Materials.

6. O'Dowd, N.P. and Shih, C.F., Family of crack-tip fields characterized by triaxiality parameter: Part I - structure of fields. Journal of Mechanics and Physics of Solids, 1991. 39(8): p. 989-1015.

7. O'Dowd, N.P. and Shih, C.F., Family of crack-tip fields characterized by triaxiality parameter: Part II - application. Journal of Mechanics and Physics of Solids, 1992. 40(5): p. 939-963.

8. Verstraete, M., De Waele, W. and Hertelé, S., Development and validation of a high constraint modified boundary layer finite element model, in Sustainable construction and design. 2011: Gent, Belgium.

9. Dodds, R.H., Shih, C.F. and Anderson, T.L., Continuum and micromechanics treatment of constraint in fracture. 1993, Office of nuclear regulatory research.

10. Henry, B.S. and Luxmoore, A.R., The stress triaxiality constraint and the Q-value as a ductile fracture parameter. Engineering Fracture Mechanics, 1997. 57(4): p. 375-390.

11. Cravero, S., Bravo, R.E. and Ernst, H.A., Fracture evaluation of cracked pipelines subjected to combined loading, in Pipeline Technology Conference. 2009: Ostend, Belgium.

12. Zhu, X.K., Jang, S.K. and Chen, Y.F., A Modification of J-Q theory and its applications. International Journal of Fracture, 2001. 111: p. 47-52.

13. Zhu, X.K. and Leis, B.N., Application of constraint correcte J-R curves to fracture analysis of pipelines. Journal of Pressure Vessel Technology, 2006. 128: p. 581-589.

14. Joyce, J.A. and Link, R.E., Application of two parameter elastic-plastic fracture mechanics to analysis of structures. Engineering Fracture Mechanics, 1997. 57(4): p. 431-446.

15. Gurson, A.L., Continuum theory of ductile rupture by nucleation and growth: Part I - yield criteria and flow rules for porous ductile media. Journal for Engineering Materials and Technology, 1977. 99: p. 215.

16. Zhang, Z.L., Thaulow, C. and Odegard, J., A complete Gurson model approach for ductile fracture. Engineering Fracture Mechanics, 2000. 67: p. 155-168.

17. Nourpanah, N. and Taheri, F., Ductile crack growth and constraint in pipelines subject to combined loadings. Engineering Fracture Mechanics, 2011. 78: p. 2010-2028.

18. Tvergaard, V., Influence of voids on shear band instabilities under plane strain condition. International Journal of Fracture Mechanics, 1981. 17(4): p. 389-407.

19. Tvergaard, V. and Needleman, A., An analysis of ductile rupture in notched bars. Journal of Mechanics and Physics of Solids, 1984. 32(6): p. 461-490.

20. Burdekin, F.M. and Xu, W.G., Effects of biaxial loading and residual stresses on constraint. Pressure Vessels and Piping, 2003. 80: p. 755-773.

21. English, S.A. and Arakere, N.K., Effects of strain-hardening exponent on two-parameter characterizations of surface-cracks under large-scale yielding. International Journal of Plasticity, 2011. 27: p. 920-939.

22. Graba, M., The influence of material properties on the $Q$-stress value near the crack tip for elasticplastic materials. Journal of Theoretical and Applied Mechanics, 2008.

23. Yuan, H. and Brocks, W., On the J-integral concept for elastic-plastic crack extension. Journal of Nuclear Engineering Design, 1991. 131: p. 157-173.

24. Thaulow, C., Ostby, E., Nyhus, B., Olden, V. and Zhang, Z.L., The philosophy of constraint correction, in International symposium on high strength steel. 2002: Stiklestad, Norway.

25. Xu, J., Zhang, Z.L., Ostby, E., Nyhus, B. and Sun, D.B., Constraint effect on the ductile crack growth resistance of circumferentially cracked pipes. Engineering Fracture Mechanics, 2010. 77: p. 671684.

26. Thaulow, C., Ostby, E., Nyhus, B., Zhang, Z.L. and Skallerud, B., Constraint correction of high strength steel: selection of test specimen and application of direct calculations. Engineering Fracture Mechanics, 2004. 71: p. 2417-2433.

27. Tyson, W.R., Shen, G. and Roy, G., Effect of biaxial stress on ECA of pipelines under strain-based design, in International Offshore and Polar Engineering Conference. 2007: Lisbon, Portugal. 
28. Pisarski, H.G. and Wignall, C.M., Fracture toughness estimation for pipeline girth welds, in International Pipeline Conference. 2002: Calgary, Alberta, Canada.

29. Cravero, S. and Ruggieri, C., Correlation of fracture behavior in high pressure pipelines with axial flaws using constraint designed test specimens - Part I: plane-strain analyses. Engineering Fracture Mechanics, 2005. 72: p. 1355-1360.

30. Xu, J., Zhang, Z.L., Ostby, E., Nyhus, B. and Sun, D.B., Effects of crack depth and specimen size on ductile crack growth of SENT and SENB specimens for fracture mechanics evaluation of pipeline steels. International Journal of Pressure Vessels and Piping, 2009. 86: p. 787-797.

31. Nourpanah, N. and Taheri, F., A numerical study on the crack tip constraint of pipelines subject to extreme plastic bending. Engineering Fracture Mechanics, 2011. 78: p. 1201-1217.

32. Lee, M.M.K., Boothman, D.P. and Luxmoore, A.R., Effects of biaxial loading on crack driving force and constraints for shallow semi-elliptical surface flaws. International Journal of Fracture, 1999. 98: p. 3754.

33. Kim, Y.-J., Chung, K.-H., Kim, J.-S. and Kim, Y.-J., Effect of biaxial loads on elastic-plastic J and crack tip constraint for cracked plates: finite element study. International Journal of Fracture, 2004. 130: p. 803-825.

34. Kibey, S.A., Minnaar, K., Cheng, W. and Wang, X., Development of a physics-based approach for the prediction of strain capacity of welded pipelines, in International Offsore and Polar Engineering Conference. 2009: Osaka, Japan.

35. Cravero, S., Bravo, R.E. and Ernst, H.A., Constraint evaluation and effects on J-R resistancecurves fro pipes under combined load conditions, in International Offshore and Polar Engineering conference. 2008: Vancouver, British Columbia, Canada.

36. Silva, L.A.L., Cravero, S. and Ruggieri, C., Correlation of fracture behavior in high pressure pipelines with axial flaws using constriant designed test specimens. Part II - 3D effects on constraint. Engineering Fracture Mechanics, 2006. 73: p. 2123-2138.

37. Berg, E., Ostby, E., Thaulow, C. and Skallerud, B., Ultimate fracture capacity of pressurized pipes with defects - Comparisons of large scale testing and numerical simulations. Engineering Fracture Mechanics, 2008. 785: p. 2352-2366.

38. Ostby, E. and Hellesvik, A.O., Large-scale experimental investigation of the effect of biaxial loading on the deformation capacity of pipes with defects. International Journal of Pressure Vessels and Piping, 2008. 85: p. 814-824.

39. Shen, G., Gianetto, J.A. and Tyson, W.R., Measurement of J-R curves using single-specimen technique on clamped SE(T) specimens, in International offshore and polar engineering conference. 2009: Osaka, Japan. 